\title{
Interactions of gut microbiota with \\ functional food components and nutraceuticals
}

5

Laparra J.M., Sanz Y.*

Microbial Ecophysiology and Nutrition Group. Institute of Agrochemistry and Food

Technology (IATA). Spanish National Research Council (CSIC). PO Box 73, 46100

Burjassot, Valencia. Spain

10 *Corresponding author: Telephone: (+34) 963900022

Fax: (+34) 963636301

E-mail: yolsanz@iata.csic.es

15 Keywords: gut mirobiota; functional foods; nutraceuticals; prebiotics; polyunsaturated fatty acids; phytochemicals 


\begin{abstract}
The human gut is populated by an array of bacterial species, which develop important metabolic and immune functions, with a marked effect on the nutritional and health status of the host. Dietary component also play beneficial roles beyond basic 5 nutrition, leading to the development of the functional food concept and nutraceuticals. Prebiotics, polyunsaturated fatty acids (PUFAs) and phytochemicals are the most well characterized dietary bioactive compounds. The beneficial effects of prebiotics mainly relay on their influence on the gut microbiota composition and their ability to generate fermentation products (short-chain fatty acids) with diverse biological roles. PUFASs

10 include the $\omega-3$ and $\omega-6$ fatty acids, whose balance may influence diverse aspects of immunity and metabolism. Moreover, interactions between PUFAs and components of the gut microbiota may also influence their biological roles. Phytochemicals are bioactive non-nutrient plant compounds, which have raised interest because of their potential effects as antioxidants, antiestrogenics, anti-inflammatory,

15 immunomodulatory, and anticarcinogenics. However, the bioavailability and effects of polyphenols greatly depend on their transformation by components of the gut microbiota. Phytochemicals and their metabolic products may also inhibit pathogenic bacteria while stimulate the growth of beneficial bacteria, exerting prebiotic-like effects. Therefore, the intestinal microbiota is both a target for nutritional intervention and a

20 factor influencing the biological activity of other food compounds acquired orally. This review focuses on the reciprocal interactions between the gut microbiota and functional food components, and the consequences of these interactions on human health.
\end{abstract}

Keywords: gut mirobiota; functional foods; nutraceuticals; prebiotics; polyunsaturated fatty acids; phytochemicals 


\section{Introduction}

The intestinal tract harbours a complex bacterial community (microbiota), integrated by more than 800 different bacterial species, which have an enormous impact on the nutritional and health status of the host. The metabolic activity developed by the gut microbiota contributes to the digestion of dietary compounds, salvage of energy, supply of (micro)nutrients and transformation of xenobiotics. Overall, a balanced gut microbiota composition confers benefits to the host, while microbial imbalances are associated with metabolic and immune-mediated disorders $(1,2)$. The composition of the gut microbiota is influenced by endogenous and environmental factors (diet,

10 antibiotic intake, xenobiotics, etc.). Of these factors, the diet is considered a major driver for changes in gut bacterial diversity that may affect its functional relationships with the host (3). In fact, the microbiome of the adult-type and infant-type microbiota has distinct gene contents to accommodate nutrient acquisition strategies to different diets (4).

15 The primary role of diet is providing sufficient nutrients to meet the basic nutritional requirements for maintenance and growth, while giving the consumer a feeling of satisfaction and well-being. In addition, some food components exert beneficial health effects beyond basic nutrition, leading to the concept of functional foods and nutraceuticals (5). Functional foods are those foods that provide benefits beyond basic 20 nutrition when consumed as part of the regular diet. Nutraceuticals are extracts containing the biologically active food components supplied in other than a food form. Dietary components with biological effects are susceptible to be metabolized by intestinal bacteria during the gastrointestinal passage, prior being absorbed. The colon has the highest bacterial load and constitutes an active site of metabolism rather than a

25 simple excretion route (6). The metabolic activity of the gut microbiota on bioactive 
food components can modify the host exposure to these components and their potential health effects. Furthermore, some functional food components influence the growth and/or metabolic activity of the gut microbiota and, thereby, its composition and functions $(7,8)$. Therefore, the intestinal microbiota is both a target for nutritional

5 intervention to improving health and a factor influencing the biological activity of other food compounds acquired orally. This review focuses on the reciprocal interactions between the gut microbiota and functional food components, and the consequences of these interactions on human health (Figure 1).

\section{Gut microbial ecology}

The human gut is populated by a vast number of bacterial species (more than 800 ) that reach the highest concentrations in the colon (up to $10^{12}$ cells per gram of faeces). The gut colonization process starts immediately after birth and the development and establishment of the infant's microbiota highly depend on environmental factors. The

15 infant's microbiota initially shows low diversity and instability, but evolves into a more stable adult-type microbiota over the first 24 months of life (9). In general, Bifidobacterium populations are dominant in the first months of life, especially in breast-fed infants (up to $90 \%$ of the total faecal bacteria) due to the bifidogenic effect of breast milk, while a more-diverse microbiota is found in formula-fed infants, weaning 20 children and adults (10). Metagenomic analyses show that in adults and weaned children the major constituents of the colonic microbiota are Bacteroides, followed by several genera belonging to the division Firmicutes, such as Eubacterium, Ruminococcus and Clostridium, and the genus Bifidobacterium. By contrast, in infants the genus Bifidobacterium is predominant and also a few genera from the family

25 Enterobacteriaceae, such as Escherichia, Raoultella, and Klebsiella (4). The 
composition of this bacterial ecosystem is dynamic and susceptible to changes driven by dietary factors and diverse disease conditions $(11,12)$.

\section{Roles of the gut microbiota in host physiology and health}

The gut microbiota develops a number of protective, immune and metabolic functions, which altogether have an enormous impact on the nutritional and health status of the host. The indigenous gut microbiota and transient bacteria (food-associated and probiotics) are known to influence the development and regulation of the host's defences, of immune and non-immune nature, via interaction with the epithelium and

10 the gut-associated lymphoid tissue (13). The intestinal epithelium constitutes a physical barrier that regulates the transcellular and paracellular transit of exogenous substances and impairs the entry of most of luminal antigens; this barrier is strengthened by the mucus layer integrated by glycoproteins (mucins) and the synthesis of antimicrobial peptides and other secretions (bile, acids, enzymes, etc.). The commensal microbiota

15 constitutes part of this primary line of defence, and participates in regulation of paracellular permeability, mucin gene expression by goblet cells and secretion of antimicrobial peptides (defensins and angiogenins) by intestinal Paneth cells. Moreover, the intestinal microbiota is essential to the postnatal development of the immune system, influencing the content of lamina propria $\mathrm{T}$ cells, immunoglobulin A producing

20 B cells, intraepithelial $\mathrm{T}$ cells and serum immunoglobulin levels (14). Based on these protective and immunomodulatory roles, some probiotic strains are acknowledged for their beneficial effects on the treatment of acute diarrhoea, prevention of antibiotic associated-diarrhoea, eradication of Helicobacter pylori infection together with antibiotics and in prevention of atopic eczema in humans $(13,15)$. 
The intestinal microbiota also affects the host metabolism, providing additional enzymes and regulating the expression of genes involved in the utilization of carbohydrates and lipids, and in drugs bioconversion (16-18). The number of genes of the collective genome (microbiome) of the microbiota exceeds by far those of the 5 human genome, encoding additional metabolic features (17, 19). Genomic and physiologic studies have demonstrated that the gut microbiota provides enzymes specialized in the utilization of non-digestible carbohydrates and host-derived glycoconjugates (e.g. mucin), deconjugation and dehydroxylation of bile acids, cholesterol reduction, biosynthesis of vitamins ( $\mathrm{K}$ and $\mathrm{B}$ group) and isoprenoids and

10 metabolism of amino acids and xenobiotics $(4,16,17)$.

The microbiome is particularly enriched in genes involved in carbohydrate metabolism and uptake, indicating that complex polysaccharides are the primary energy source for the colonic microbiota (4). The genome sequence of Bifidobacterium longum also has a large number of predicted proteins (more than $8 \%$ ) related to the catabolism

15 of oligo- and poly-saccharides released from non-digestible plant polymers (20). Some of the most abundant bacterial enzymes involved in the degradation of complex polysaccharides and xenobiotics are $\beta$-glycosidases and $\beta$-glucuronidases, which may play both beneficial and harmful roles (21). Glycosidase activities present in the human colonic microbiota act on plant glucosides contributing to nutrient utilization and, in 20 some cases, to the generation of biologically active aglycones with other health benefits (e.g. from isoflavones). The utilization of complex dietary polysaccharides by the microbiota seems to contribute to harvest energy from the diet, which may represent $10 \%$ of the daily energy supply (22). Fermentation of dietary polysaccharides leads to the generation of short-chain fatty acids (SCFAs) (e.g. acetate, butyrate and propionate) 25 and other gases (e.g. carbon dioxide and hydrogen). The principal SCFAs (acetate, 
propionate and butyrate) are metabolized by the colonic epithelium (butyrate), liver (propionate) and muscle (acetate) and exert different functions. Butyrate is utilized by enterocytes and generally regarded as a healthy metabolite, since it positively influences cell growth and differentiation, and exerts anti-inflammatory effects (23). Acetate and 5 propionate can access the portal circulation and oppositely impact lipid metabolism. While acetate seems to contribute to lipid and cholesterol synthesis in the liver, propionate can inhibit the effects of acetate. Unlikely $\beta$-glycosidases, $\beta$-glucuronidases usually liberate toxins and mutagens that have been glucuronated in the liver and excreted into the gut with the bile. This can lead to the accumulation high local

10 concentrations of carcinogenic compounds within the gut, thus increasing the risk of carcinogenesis. Furthermore, reuptake of the deconjugated compound from the gut and re-glucuronidation in the liver lead to an enterohepatic circulation of xenobiotic compounds, which increases their retention time in the body. In the colonic microbiota, bacterial $\beta$-glucosidases seem to be more widespread than $\beta$-glucuronidases. Studies

15 carried out in 40 bacterial strains, which are representative of dominant bacteria in human faeces, show that more than half of the low $\mathrm{G}+\mathrm{C} \%$ Gram-positive Firmicutes have $\beta$-glucosidase activity, while $\beta$-glucuronidase activity is only present in some Firmicutes, within the clostridial clusters XIVa and IV (21). Most of the Bifidobacterium spp. and Bacteroides thetaiotaomicron have $\beta$-glucosidase activity.

20 Moreover, the level of exposure to glycosides in the colon, which is dependent on the type of diet consumed, could affect the induction of enzyme activity levels in some members of the gut microbiota and, therefore, influence their functions (21). Specific glycosidases (xylanases, arabinofuranosidases and xylosidases) required for complete degradation of complex polysaccharides present in plant cell walls, such as arabinans and arabinoxylans, are also encoded by the total faecal microbiota and by strains of the 
main bacterial genera (Bifidobacterium and Bacteroides) (24, 25). Bifidobacterium longum subsp. infantis ATCC 15697, an isolate from the infant gut, is also equipped with genes and enzymes allowing the preferential consumption of small mass oligosaccharides, which represent $63.9 \%$ of the total human milk oligosaccharides 5 available $(26,27)$. In addition, genes coding for an endo-alpha-Nacetylgalactosaminidase and a 1,2-alpha-L-fucosidase, which hydrolyse high-molecular weight mucin, are present in several Bifidobacterium bifidum strains (28).

Gut bacterial enzymes are also involved in the metabolism of cholesterol and bile acids. Cholesterol can be reduced to coprostanol by the commensal microbiota, 10 increasing its secretion in faeces. Bile acids are synthesized from cholesterol in the liver mostly as the primary bile acids, cholic acid and chenodeoxycholic acid. Intestinal bacteria are also able to convert these acids into various types of secondary bile acids by catalysing their deconjugation and dehydroxylation, thereby limiting the solubilization and absorption of dietary lipids throughout the intestine (29). However, these activities

15 can also lead to the generation of secondary bile acids, some of which (deoxycholic acid and lithocholic acid) are considered possible carcinogens. Bacteroides intestinalis and secondarily Bacteroides fragilis and E. coli are potentially involved in the generation of secondary bile acids in the colon (30).

The metabolic activity of the microbiota can also contribute to the supply of amino

20 acids required by humans. In the presence of fermentable carbohydrate substrates (e.g. non-starch polysaccharides, resistant starch and oligosaccharides), colonic bacteria grow and actively synthesize protein, which can be a soured of amino acids for the host (31). Although it is difficult to quantify the protein synthesis and turnover within the large intestine, at lest from 1 to $20 \%$ of circulating plasma lysine and threonine in adult 25 human subjects is derived form the intestinal microbiota, as estimated by using labelled 
amino acids (16). Nevertheless, the metabolic activities of the microbiota involved in the degradation of food related nitrogen compounds (e.g. nitrocompounds, sulphurcontaining compounds and amino acids) can lead to the generation of potentially carcinogenetic substances (32).

The commensal microbiota also regulates the expression of genes involved in the processing and absorption of dietary carbohydrates and complex lipids by the host, which altogether lead to body weight gain and increased fat storage. Gut colonization by commensal bacteria increases the expression of an intestinal monosaccharide transporter and key enzymes (acetyl-CoA carboxylase and fatty acid synthase) of de novo fatty acid

10 biosynthetic pathways $(33,34)$. The colonization of germ-free mice also reduces the levels of circulating fasting-induced adipose factor (Fiaf) and the skeletal muscle and liver levels of phosphorylated AMP-activated protein kinase, contributing to fat storage (35). Furthermore, comparisons between germ-free and colonized rat demonstrated that the intestinal microbiota affect levels of xenobiotic-metabolizing enzymes in large 15 intestine and liver, including glutathione transferases, gastrointestinal glutathione peroxidase, epoxide hydrolases, $\mathrm{N}$-acetyltransferases, and cytochrome P450 activities, which might affect the host ability to detoxify different compounds $(36,37)$.

Therefore, the intestinal tract is inhabited by a complex microbiota that develops strategies to regulate nutrient acquisition and utilization in symbiosis with the host and 20 in response to the diet. The biochemical activity this complex ecosystem generates healthy as well as potentially harmful compounds from the diet and their balance is essential to maintain a healthy status. This could be achieved by diverse nutritional strategies, including the administration of probiotic bacteria and other functional food components, whose roles and interactions with the microbiota are reviewed in the 25 following sections. 


\section{Prebiotics and gut microbiota}

Prebiotics are nondigestible food ingredients, mostly oligosaccharides, which beneficially affect the host by stimulating growth, activity or both of specific intestinal

5 bacteria (38). The criteria that have to fulfil a prebiotic include, (1) resistance to gastric acidity and mammalian enzymes; (2) susceptibility to be fermented by gut microbiota; and (3) ability to stimulate the growth and/or activity of beneficial intestinal bacteria. The possible beneficial effects of prebiotics include the control intestinal transit time and bowel habits, and reduction of risk of atherosclerosis, osteoporosis, obesity, type-2

10 diabetes, cancer, infections and allergies, although their effectiveness in humans is still controversial (38). The biological effects of prebiotics mainly depend on their influence on the gut microbiota composition and derived metabolites; although some roles could be due to their own structure and direct action (e.g. inhibition of pathogen adhesion by homology with bacterial receptors).

15 Galacto-oligosaccharides (GOS) and inulin-derivatives (e.g. fructo-oligosaccharides [FOS]) are the prebiotics most commonly commercialized in Europe. GOS are nondigestible oligosaccharides derived from lactose that are found naturally in human milk and consist of chains of galactose monomers. These prebiotics provide beneficial effects in the gastrointestinal tract by stimulating growth of specific members of the intestinal

20 microbiota (e.g. bifidobacteria). GOS alone or combined with FOS are mainly added to infant formula to promote the prevalence of a microbiota composition similar to that resulting from breast-feeding during both milk-feeding and the weaning period. This dietary strategy may increase the total amount of faecal bifidobacteria and favour a Bifidobacterium species composition resembling that of breast-fed infants $(39,40)$. Moreover, GOS may structurally mimic the pathogen binding sites that coat the surface 
of gastrointestinal epithelial cells and thereby may inhibit enteric pathogen adhesion and infection (41).

Inulin and its hydrolytic product (oligofructose) are fructans that are linked by $\beta$-(21) linkages and differentiated by the number of fructose monomers. Inulin has a high 5 number (10-60) and oligofructose derivatives have a low (3-7) number of fructose monomers. They naturally occur at high concentrations in plant-foods such as onion, asparagus, wheat, artichoke, etc. (42), and exhibit different functional attributes (43), including modulation of the gut microbiota, prevention of pathogens adhesion and colonization, induction of anti-inflammatory effects, reduction of food intake, 10 modulation of bowel habits and regulation of alterations in lipid and glucose metabolism. Most of these effects are derived from their structural resistance to mammalian digestive enzymes and their ability to stimulate the growth of beneficial bacteria (e.g. bifidobacteria and lactobacilli) in the colon and to increase the generation of SCFAs with diverse biological roles $(38,44-47)$. The effects of these prebiotics on

15 immune functions may be due to the induced changes on the gut microbiota and/or to the effects of the generated SCFAs via binding to SCFA receptors on leucocytes (48). Studies using long-chain inulin have evidenced beneficial effects on bowel inflammation reducing the production of pro-inflammatory biomarkers, along with an increase in intestinal bifidobacteria and lactobacilli (49-53). SCFA may also regulate

20 intestinal fat absorption since butyrate, for instance, impairs lipid transport in vitro in Caco-2 cells (54-55). In addition, inulin and inulin-type fructans, are considered dietary soluble fiber, and directly modulate bowel habits slowing gatric emptying and intestine transit time, delaying absorption of glucose and improving alterations in glucose metabolism (56). 
Furthermore, dietary fibre including some non-starch polysaccharides, such as cellulose, dextrins, chitins, pectins, beta-glucans, and waxes, and lignin can modulate the transit time through the gut providing similar beneficial effects as those of inulintype fructans. These compounds are found in many foods such as cereal, nuts, etc. They

5 are also partially susceptible to bacterial fermentation and may induce changes in bacterial populations, particularly in number of bifidobacteria and lactobacilli. These dietary soluble fibers have been shown to exert additional beneficial effects, for instance improving gut barrier function in vitro (57) and in vivo (58-60), which could be partially a consequence of their effect on the microbiota composition.

\section{Polyunsaturated fatty acids (PUFAs) and gut microbiota}

PUFA are fatty acids that contain more than one double bond, which are separated from each other by a single methylene group. The $\omega-3$ fatty acids (linolenic, ecosapentaenoic and docosahexaenoic acids) and $\omega-6$ fatty acids (linoleic and

15 arachidonic acids) are the best characterized so far. The biological effects of the $\omega-3$ and $\omega-6$ fatty acids are largely mediated by their mutual interactions. The possible underying mechanisms by which PUFA exert their beneficial effects on health are diverse, involving the formation of prostacyclins and thromboxanes, pro-inflammatory cyokine production (tumor necrosis factor alpha and interleukin-1), modulation of the hypothalamic-pituitary-adrenal anti-inflammatory responses, and induction of the release of acetylcholine (61). Thus, diets rich in PUFAs have been shown to positively influence immune function, blood pressure, cholesterol and triglycerides levels, and cardiovascular function in animals and humans (62-65).

The adult microbiome is not particularly enriched in genes involved in fatty acid metabolism (4); however, some interactions of PUFAs with the indigenous microbiota 
and some probiotics have been reported, which might affect the biological roles of both. In vitro studies on the effects of PUFAs (linoleic, gamma-linolenic, arachidonic, alphalinolenic and docosahexaenoic acids) on the growth and adhesion of different Lactobacillus strains (Lactobacillus rhamnosus GG, Lactobacillus casei Shirota and

5 Lactobacillus delbrueckii subsp bulgaricus) have shown different results depending on the strain. High concentrations of PUFA $(10-40 \mu \mathrm{g} / \mathrm{ml})$ inhibited growth and adhesion to mucus of all tested bacterial strains, whilst low concentrations of gamma-linolenic acid and arachidonic acid $(5 \mu \mathrm{g} / \mathrm{ml})$ promoted growth and mucus adhesion of $L$. casei Shirota (66). PUFAs supplemented into the growth medium can also be utilized by

10 Lactobacillus strains, generating different products (67). Interconversions were detected in octadecanoic acids (18:1), their methylenated derivatives (19:cyc), conjugated linoleic acid and eicosapentaenoic acid proportions. These results suggest that Lactobacillus may have a potential as regulators of PUFA absorption in vivo. The administration of PUFAs has also positively influenced the adhesion of Lactobacillus to

15 the jejunal mucosa of gnotobiotic piglets, indicating that the intake of these fatty acids may influence the intestinal levels of this bacterial group (68). In fish fed diets containing PUFAs, lactic acid bacteria dominated among the Gram-positive bacteria within the epithelial mucosa, suggesting that dietary fatty acids affect the attachment sites for the gastrointestinal microbiota, possibly by modifying the fatty acid composition of the intestine wall. In a small clinical trial, the administration of an infant formula supplemented with Bifidobacterium Bb-12 or Lactobacillus GG to infants with atopic eczema $(n=15)$ exerted some effects on plasma lipids (69). Of neutral lipids, alpha-linolenic acid (18:3 n-3) proportions were reduced by the probiotic supplementation and, in relation to phospholipids, only Bifidobacterium Bb-12 supplementation increased the proportion of alpha-linolenic acid. Therefore, the 
evidence suggests that some physiological effects of probiotics could be associated with the interactions between probiotics and dietary PUFA, although further studies are needed to confirm this hypothesis in vivo.

\section{Phytochemicals and gut microbiota}

Phytochemicals are defined as bioactive non-nutrient plant compounds present in fruits, vegetables, grains, and other plant foods, whose ingestion has been linked to reductions in risk of major chronic diseases (70). The different compounds included in this group can be classified according to common structural features into carotenoids,

10 phenolics, alkaloids and nitrogen-containing and organosulfur compounds. Phenolics, flavonoids and phytoestrogens have raised particular interest because of their potential effects as antioxidants (71), antiestrogenics (72), anti-inflammatory and immunomodulatory (73-77), cardioprotectives and anticarcinogenics $(70,71,78)$ compounds (Table 1).

15 The bioavailability and effects of polyphenols greatly depend on their transformation by specific components of the gut microbiota via esterase, glucosidase, demethylation, dehydroxylation and decarboxylation activities (6). Many dietary polyphenols are glycosides that are transformed into aglycones by commensal bacterial glycohydrolases, thereby modifying their bioavailability and affecting positive or

20 negatively their activities and/or functional effects on the mammalian tissues $(79,80)$. Polyphenols are commonly present in plant foods as a bound form, most often conjugated as glycosides, and most of them are metabolized by gut microbiota resulting in formation of aglycones $(81,82)$. The microbiota metabolites of polyphenols are better absorbed in the intestine, and their entero-hepatic circulation ensures that the 
residence time in plasma for the metabolites is extended compared to that of their parent compounds, and finally are excreted via urine.

The gut microbiota has proved to be essential for the production of active isoflavone metabolites with oestrogen-like activity; additionally, the metabolites produced exhibit 5 different anti-inflammatory properties (73). Similarly, the flavonoid quercetin generated by gut microbial enzymes exerts a higher effect in the down-regulation of the inflammatory responses than the glycosylated form present in vegetables (quercitrin or 3-rhamnosylquercetin) (83). This effect is exerted by inhibiting cytokine and inducible nitric oxide synthase expression through inhibition of the NF-kappaB pathway both in

10 vitro and in vivo (83). In contrast, the ellagitanin punicalagin that is the most potent antioxidant found in pomegranate juice is extensively metabolized to hydroxy-6Hdibenzopyran-6-one derivatives, which did not show significant antioxidant activity compared to punicalagin (84).

Phytochemicals and their derived products can also affect the intestinal ecology as a

15 significant part of them are not fully absorbed and are metabolised in the liver, excreted through the bile as glucuronides and accumulated in the ileal and colorectal lumen (85). For example, the intake of flavonol-rich foods has been shown to modify the composition of the gut microbiota, exerting prebiotic-like effects (86). Unabsorbed dietary phenolics and their metabolites have been shown to exert antimicrobial or 20 bacteriostatic activities (87). These metabolites selectively inhibit pathogen growth and stimulate the growth of commensal bacteria, including also some recognized probiotics $(87,88)$, thus influencing the microbiota composition. Plant phenolic compounds from olives (89), tea (87), wine (88) and berries $(90,91)$ have demonstrated antimicrobial properties. Tea phenolics have shown to inhibited the growth of Bacteroides spp., 25 Clostridium spp. (C. perfringens and C. difficile), Escherichia coli and Salmonella 
typhimurium (87). The level of inhibition was related to the chemical structure of the compound and bacterial species. In this sense, caffeic acid generally exerted a more significant inhibitory effect on pathogen growth than epicatechin, catechin, 3-Omethylgallic acid, and gallic acid. Another in vitro study showed that $(+)$-catechin 5 increased the counts of Clostridium coccoides-Eubacterium rectale group and Escherichia coli, but inhibited those of Clostridium histolyticum (86). The effects of (-)epicatechin were less pronounced increasing the growth of Clostridium coccoidesEubacterium rectale group (86). Interestingly, the growth of beneficial bacteria (Bifidobacterium spp and Lactobacillus spp) was relatively unaffected or favoured (86,

10 87). Resveratrol, a potent antioxidant found in wine, favoured the increase of Bifidobacterium and Lactobacillus counts (88) and abolished the expression of virulence factors of Proteus mirabilis to invade human urothelial cells (92). Anthocyanins from berries also have proved to inhibit the growth of pathogenic Staphylococcus spp, Salmonella spp, Helicobacter pylori and Bacillus cereus (90, 91).

15 Phenolics, and flavonoids may also reduce the adhesion ability of L. rhamnosus to intestinal epithelial cells (93). Tea catechins have also been shown to modify mucin content of the ileum which could modulate bacterial adhesion and colonization (94). Therefore, polyphenols appear to have potential to confer health benefits via modulation the gut microecology. However, the effects of interplay between polyphenols and

20 specific gut microbiota functions remain largely uncharacterized.

\section{Conclusions and future perspectives}

The gut microbiota exerts an enormous impact on the nutritional and health status of the host via modulation of the immune and metabolic functions. The microbiome provides additional enzymatic activities involved in the transformation of dietary 
compounds. Food bioactive compounds also exert significant effects on the intestinal environment, modulating the gut microbiota composition and probably its functional effects on mammalian tissues. This evidence is changing the way the biological roles of functional food components are being investigated since their metabolites and effects

5 may depend on the gut microbiota and even change from one individual to another. Advances on the knowledge of the interactions between bioactive food compounds and specific intestinal bacteria could contribute to a better understanding of both positive and negative interactions in vivo and to the identification of new functional microorganisms inhabiting our intestinal tract.

\section{Acknowledgements}

This work was supported by grants AGL2008-01440/ALI and Consolider Fun-C-Food CSD2007-00063 from the Spanish Ministry of Science and Innovation (MICINN, Spain) and PIF08-010-4 form CSIC. J. M. Laparra has a postdoctoral contract of the 15 programme "Juan de la Cierva” (MICINN, Spain). 


\section{References}

[1] Nadal I, Donat E, Ribes-Koninckx C, Calabuig M, Sanz Y. Imbalance in the composition of the duodenal microbiota of children with coeliac disease. J Med Microbiol. 2007; 56:1669-74.

[2] Santacruz A, Marcos A, Wärnberg J, Martí A, Martin-Matillas M, Campoy C, Moreno LA, Veiga O, Redondo-Figuero C, Garagorri JM, Azcona C, Delgado M, García-Fuentes M, Collado MC, Sanz Y.Interplay between weight loss and gut microbiota composition in overweight adolescents. Obesity 2009; 17:1906-15.

10 [3] Ley RE, Lozupone CA, Hamady M, Knight R, Gordon JI. Worlds within worlds: evolution of the vertebrate gut microbiota. Nat Rev Microbiol 2008; 6: 776-88.

[4] Kurokawa K, Itoh T, Kuwahara T, Oshima K, Toh H, Toyoda A, Takami H, Morita H, Sharma VK, Srivastava TP, Taylor TD, Noguchi H, Mori H, Ogura Y, Ehrlich DS, Itoh K, Takagi T, Sakaki Y, Hayashi T, Hattori M. Comparative 15 metagenomics revealed commonly enriched gene sets in human gut microbiomes. DNA Res. 2007; 14: 169-81.

[5] Roberfroid MB. Prebiotics and probiotics: are they functional foods?. Am J Clin Nutr 2000; 71: 1682S-1687S.

[6] Aura AM. Microbial metabolism of dietary phenolic compounds in the colon. Phytochem Rev 2008; 7: 407-29.

[7] Campbell JH, Fahey GC Jr, Wolf BW. Selected indigestible oligosaccharides affect large bowel mass, cecal and fecal short-chain fatty acids, $\mathrm{pH}$, and microflora in rats. J Nutr. 1997; 127: 130-6.

[8] Gibson GR, McCartney AL, Rastall RA. Prebiotics and resistance to gastrointestinal infections. Br J Nutr. 2005; 93: S31-S34. 
[9] Zoetendal EG, Akkermans AD, De Vos WM. Temperature gradient gel electrophoresis analysis of 16S rRNA from human fecal samples reveals stable and host-specific communities of active bacteria. Appl Environ Microbiol. 1998; 64: 3854-9.

5 [10] Gueimonde M, Salminen S, Isolauri. Presence of specific antibiotic (tet) resistance genes in infant faecal microbiota. FEMS Immunol Med Microbiol. 2006; 48: 215.

[11] Xu J, Mahowald MA, Ley RE, Lozupone CA, Hamady M, Martens EC, Henrissat B, Coutinho PM, Minx P, Latreille P, Cordum H, Van Brunt A, Kim K, Fulton RS, Fulton LA, Clifton SW, Wilson RK, Knight RD, Gordon JI. Evolution of Symbiotic Bacteria in the Distal Human Intestine. PLoS Biol 2007; 19: e156.

[12] Sanz Y, Sánchez E, De Palma G, Medina M, Marcos A, Nova E. Indigenous gut microbiota, probiotics, and coeliac disease. In: Child Nutrition \& Physiology. Linda T. Overton \& M R. Ewente, Eds. 2008, pp. 210-224. Nova Science Publishers, Inc, NY, USA.

[13] Sanz Y, De Palma G. Gut microbiota and probiotics in modulation of epithelium and gut-associated lymphoid tissue function. Int Rev Immunol. 2009. In press

[14] Tlaskalová-Hogenová H, Stepánková R, Hudcovic T, Tucková L, Cukrowska B, Lodinová-Zádníková R, Kozáková H, Rossmann P, Bártová J, Sokol D, Funda DP, Borovská D, Reháková Z, Sinkora J, Hofman J, Drastich P, Kokesová A. Comensal bacteria (normal microflora), mucosal immunity and chronic inflammatory and autoimmune diseases. Immunol. Lett. 2004; 93: 97-108.

[15] Kalliomäki M, Salminen S, Poussa T, Isolauri E. Probiotics during the first 7 years of life: a cumulative risk reduction of eczema in a randomized, placebo-controlled trial. J Allergy Clin Immunol. 2007 Apr;119(4):1019-21. 
[16] Hooper LV, Midtvedt T, Gordon JI. How host-microbial interactions shape the nutrient environment of the mammalian intestine. Annu Rev Nutr 2002; 22: 283307.

[17] Gill SR, Pop M, Deboy RT, Eckburg PB, Turnbaugh PJ, Samuel BS, Gordon JI, Relman DA, Fraser-Liggett CM, Nelson KE. Metagenomic analysis of the human distal gut microbiome. Science 2006, 312: 1355-59.

[18] Wilson ID, Nicholson JK. The role of gut microbiota in drug response. Curr Pharm Des. 2009; 15: 1519-23.

[19]. Turnbaugh PJ, Ley RE, Hamady M, Fraser-Liggett CM, Knight R, Gordon JI. The human microbiome project. Nature 2007; 449: 804-10.

[20] Schell MA, Karmirantzou M, Snel B, Vilanova D, Berger B, Pessi G, Zwahlen MC, Desiere F, Bork P, Delley M, Pridmore RD, Arigoni F. The genome sequence of Bifidobacterium longum reflects its adaptation to the human gastrointestinal tract. Proc Natl Acad Sci U S A. 2002; 99: 14422-7.

15 [21] Dabek M, McCrae SI, Stevens VJ, Duncan SH, Louis P. Distribution of betaglucosidase and beta-glucuronidase activity and of beta-glucuronidase gene gus in human colonic bacteria. FEMS Microbiol Ecol. 2008; 66: 487-95.

[22] Flint HJ, Bayer EA, Rincon MT, Lamed R, White BA. Polysaccharide utilization by gut bacteria: potential for new insights from genomic analysis. Nat Rev Microbiol 2008; 6: 121-31.

[23] Hamer HM, Jonkers D, Venema K. The role of butyrate on colonic function. Aliment Pharmacol Ther. 20082; 7: 104-19.

[24] Gueimonde M, Noriega L, Margolles A, de los Reyes-Gavilán CG. Induction of alpha-L-arabinofuranosidase activity by monomeric carbohydrates in 
Bifidobacterium longum and ubiquity of encoding genes. Arch Microbiol. 2007; 187: $145-53$.

[25] Grootaert C, Van den Abbeele P, Marzorati M, Broekaert WF, Courtin CM, Delcour JA, Verstraete W, Van de Wiele T. Comparison of prebiotic effects of arabinoxylan oligosaccharides and inulin in a simulator of the human intestinal microbial ecosystem. FEMS Microbiol Ecol. 2009; 69: 231-42.

[26] LoCascio RG, Ninonuevo MR, Freeman SL, Sela DA, Grimm R, Lebrilla CB, Mills DA, German JB. Glycoprofiling of bifidobacterial consumption of human milk oligosaccharides demonstrates strain specific, preferential consumption of small chain glycans secreted in early human lactation. J Agric Food Chem. 2007;55: 8914-9.

[27] Sela DA, Chapman J, Adeuya A, Kim JH, Chen F, Whitehead TR, Lapidus A, Rokhsar DS, Lebrilla CB, German JB, Price NP, Richardson PM, Mills DA. The genome sequence of Bifidobacterium longum subsp. infantis reveals adaptations for milk utilization within the infant microbiome. Proc Natl Acad Sci U S A. $2008 ; 105: 18964-9$.

[28] Ruas-Madiedo P, Gueimonde M, Fernández-García M, de los Reyes-Gavilán CG,Margolles A. Mucin degradation by Bifidobacterium strains isolated from the human intestinal microbiota. Appl Environ Microbiol. 2008; 74: 1936-40.

[29] Ridlon JM, Kang DJ, Hylemon PB. Bile salt biotransformations by human intestinal bacteria. J Lip Res. 2006; 47: 241-59.

[30] Fukiya S, Arata M, Kawashima H, Yoshida D, Kaneko M, Minamida K, Watanabe J, Ogura Y, Uchida K, Itoh K, Wada M, Ito S, Yokota A. Conversion of cholic acid and chenodeoxycholic acid into their 7-oxo derivatives by Bacteroides 
intestinalis AM-1 isolated from human feces. FEMS Microbiol Lett. 2009; 293: 263-70.

[31] Cummings JH, Macfarlane GT. Role of intestinal bacteria in nutrient metabolism. JPEN J Parenter Enteral Nutr. 1997 Nov-Dec;21(6):357-65.

5 [32] Rowland IR. The role of the gastrointestinal microbiota in colorectal cancer. Curr Pharm Des. 2009; 15: 1524-7.

[33] Hooper LV, Wong MH, Thelin A, Hansson L, Falk PG, Gordon JI. Molecular analysis of commensal host-microbial relationships in the intestine. Science 2001; 291: 881-84.

10 [34] Bäckhed F, Ding H, Wang T, Hooper LV, Koh GY, Nagy A, Semenkovich CF, Gordon JI. The gut microbiota as an environmental factor that regulates fat storage. Proc Natl Acad Sci U S A. 2004; 101: 15718-723.

[35] Bäckhed F, Manchester JK, Semenkovich CF, Gordon JI. Mechanisms underlying the resistance to diet-induced obesity in germ-free mice. Proc Natl Acad Sci U S A. $2007 ; 104: 979-84$.

[36] Overvik E, Lindeskog P, Midtvedt T, Gustafsson JA. Mutagen excretion and cytochrome P-450-dependent activity in germfree and conventional rats fed a diet containing fried meat. Food Chem Toxicol. 1990; 28: 253-61.

[37] Meinl W, Sczesny S, Brigelius-Flohé R, Blaut M, Glatt H. Impact of gut microbiota on intestinal and hepatic levels of phase 2 xenobiotic-metabolizing enzymes in the rat. Drug Metab Dispos. 2009; 37: 1179-86.

[38]. Roberfroid MB. Prebiotics: The concept revisited. J Nutr 2007; 137: 830S-837S.

[39] Haarman M, Knol J. Quantitative real-time PCR assays to identify and quantify fecal Bifidobacterium species in infants receiving a prebiotic infant formula. Appl Environ Microbiol. 2005; 71: 2318-24. 
[40] Scholtens PA, Alles MS, Bindels JG, van der Linde EG, Tolboom JJ, Knol J. Bifidogenic effects of solid weaning foods with added prebiotic oligosaccharides: a randomised controlled clinical trial. J Pediatr Gastroenterol Nutr. 2006; 42: 55359.

5 [41] Shoaf K, Mulvey GL, Armstrong GD, Hutkins RW. Prebiotic galactooligosaccharides reduce adherence of enteropathogenic Escherichia coli to tissue culture cells. Infect Immun. 2006; 74: 6920-28.

[42] Gibson GR, Wills CL, Van Loo J. Non-digestible oligosaccharides and bifidobacteria - implication for health. Int Sugar J. 1994; 96: 381-87.

10 [43] Mizota T. Functional and nutritional foods containing bifidogenic factors. Bull Int Dairy Found. 1996; 313: 31-35.

[44] Gibson GR, Wang X. Regulatory effect of bifidobacteria on the growth of other colonic bacteria. J Appl Bacteriol. 1994; 77: 412-20.

[45] Roberfroid MB, Van Loo JAE, Gibson GR. The bifidogenic nature of chicory inulin and its hydrolysis products. J Nutr. 1998; 128: 11-9.

[46] Levrat MA, Rémésy C, Demigné C. High propionic-acid fermentations and mineral accumulation in the cecum of rats adapted to different levels of inulin. $\mathrm{J}$ Nutr. 1991; 121: 1730-7.

[47] Kleessen B, Hartman L, Blaut M. Oligofructose and long chain inulin influence the gut microbial ecology of rats associared with a human faecal flora. Br J Nutr. 2001; 86: 291-300.

[48] Watzl B, Girrbach S, Roller M. Inulin, oligofructose and immunomodulation. Br J Nutr. 2005; 93: S49-S55 
[49] Videla S, Vilaseca J, Antolin M, Garcia-Lafuente A, Guarner F, Crespo E, Casalots J, Salas A, Malagelada JR. Dietary inulin improves distal colitis induced by dextran sodium sulfate in the rat. Am J. Gastroenterol. 2001; 96: 1486-93.

[50] Welters CF, Heineman E, Thunnissen FB, van den Bogaard AE, Soeters PB, Baeten CG. Effect of dietary inulin supplementation on inflammation of pouch mucosa in patients with an ileal pouch-anal anastomosis. Dis Colon Rectum. 2002; 45: 621-27.

[51] Hoentjen F, Welling G, Harmsen H, Zhang X, Snart J, Tannock G, Lien K, Churchill T, Lupicki M, Dieleman L. Reduction of colitis in HLA-B27 transgenic rats is associated with microflora changes and immunomodulation. Inflamm Bowel Dis. 2005; 11: 977-85.

[52] Lindsay JO, Whelan K, Stragg AJ, Gobin P, Al-Hassi HO, Rayment N, Kamm MA, Knight SC, Forbes A. Clinical, microbiological, and inmunological effects of fructo-oligosaccharide in patients with Crohn's disease. Gut. 2006; 55: 348-55.

15 [53] Leenen CHM, Dieleman L. Inulin and oligofructose in chronic inflammatory bowel disease. J Nutr. 2007; 137: 2572S-2575S.

[54] Marcil V, Delvin E, Garofalo C, Levy E. Butyrate impairs lipid transport by inhibiting microsomal triglyceride transfer protein in Caco-2 cells. J Nutr. 2003; 133: $2180-2183$.

[55] Borthakur A, Saksena S, Gill RK, Alrefai WA, Ramaswamy K, Dudeja PK. Regulation of monocarboxylate transporter 1 (MCT1) promoter by butyrate in human intestinal epithelial cells: involvement of NF-kappaB pathway. J Cell Biochem. 2008 Apr 1;103(5):1452-63.

25 [56] Roberfroid, M.B. Introducing inulin-type fructans. Br J Nutr. 2005; 93: S13-S25. 
[57] Napolitano A, Costabile A, Martin-Pelaez S, Vitaglione P, Klinder A, Gibson GR, Fogliano V. Potential prebiotic activity of oligosaccharides obtained by enzymatic conversion of durum wheat insoluble dietary fibre into soluble dietary fibre. Nutr Metab Cardiovasc Dis 2009; 19: 283-90.

5 [58] Howard MD, Gordon DT, Garleb KA, Kerley MS. Dietary fructooligosaccharide, xylooligosaccharide and gum arabic have variable effects on cecal and colonic microbiota and epithelial cell proliferation in mice and rats. J Nutr. 1995; 125: 2604-9.

[59] Durmic Z, Pethic DW, Pluske JR, Hampson DJ. Changes in Bacterial populations in the colon of pigs fed different sources of dietary fibre, and the development of swine dysentery after experimental infection. J Appl Microbiol 1998; 85: 574-82.

[60] Gómez-Conde MS, Garcia J, Chamorro S, Eiras P, Rebollar PG, Pérez de Rozas A, Badiola I, de Blas C, Carabaño R. Neutral detergent-soluble fiber improves gut barrier function in twenty-five-day-old weaned rabbits. J Animal Sci 2007; 85: $3313-21$.

[61] Das UN. Beneficial effect(s) of n-3 fatty acids in cardiovascular diseases: but, why and how?. Prostaglandins Leukot Essent Fatty Acids. 2000, 63, 351-362.

[62] Russo C, Olivieri O, Girelli D, Azzini M, Stanzial AM, Guarini P, Friso S, De Franceschi L, Corrocher R. Omega-3 polyunsaturated fatty acid supplements and ambulatory blood pressure monitoring parameters in patients with mild essential hypertension. J. Hypertens. 1995; 13: 1823-26.

[63] Kawasaki T, Seki E, Osajima K, Yoshida M, Asada K, Matsui T, Osajima Y. Antihypertensive effect of valyl-tyrosine, a short chain peptide derived from sardine muscle hydrolyzate, on mild hypertensive subjects. J. Hum. Hypertens. 2000; 14: 519-23. 
[64] Straniero S, Cavallini G, Donati A, Metelli MR, Tamburini I, Pietrini P, Bergamini E. Deficiency and supplementation of PUFA in the diet have similar effects on the age-associated changes in rat-plasma cholesterol levels. Mech Ageing Dev 2008; 129: 759-62.

5 [65] Chen ZY, Peng C, Jiao R, Wong YM, Yang N, Huang Y. Anti-hypertensive nutraceuticals and functional foods. J Agric Food Chem 2009; 57: 4485-89.

[66] Kankaanpää PE, Salminen SJ, Isolauri E, Lee YK. The influence of polyunsaturated fatty acids on probiotic growth and adhesion. FEMS Microbiol Lett. 2001; 194: 149-53.

10 [67] Kankaanpää P, Yang B, Kallio H, Isolauri E, Salminen S. Effects of polyunsaturated fatty acids in growth medium on lipid composition and on physicochemical surface properties of lactobacilli. Appl Environ Microbiol. 2004; 70: $129-36$.

[68] Bomba A, Nemcová R, Gancarcíková S, Herich R, Guba P, Mudronová D. Improvement of the probiotic effect of micro-organisms by their combination with maltodextrins, fructo-oligosaccharides and polyunsaturated fatty acids. Br J Nutr. 2002; Suppl 1: S95-9.

[69] Kankaanpää PE, Yang B, Kallio HP, Isolauri E, Salminen SJ. Influence of probiotic supplemented infant formula on composition of plasma lipids in atopic infants. J Nutr Biochem. 2002; 13: 364-69.

[70] Liu RH. Potential synergy of phytochemicals in cancer prevention: Mechanism of action. J Nutr. 2004; 134: 3479S-85S.

[71] Hertog MG, Feskens EJ, Hollman PC, Katan MB, Kromhout D. Dietary antioxidant flavonoids and risk of coronary heart disease: the Zutphen Elderly Study. Lancet 1993; 342: 1007-11. 
[72] Yuan J, Wang J, Liu X. Metabolism of dietary soy isoflavones to equol by human intestinal microflora;implications for health. Mol. Nutr. Food Res. 2007; 51: 76581.

[73] Park JS, Woo MS, Kim DH, Hyun JW, Kim WK, Lee JC, Kim HS. Antiinflammatory mechanisms of isoflavone metabolites in lipopolysaccharidestimulated microglial cells. J Pharmacol Exp Ther. 2007; 320: 1237-45.

[74]. Ruiz PA, Haller D. Functional diversity of flavonoids in the inhibition of the proinflammatory NF-kappaB, IRF, and Akt signaling pathways in murine intestinal epithelial cells. J Nutr. 2006; 136: 664-71.

10 [75] Ruiz PA, Braune A, Hölzwimmer G, Quintanilla-Fend L, Haller D. Quercetin inhibits TNF-induced NF-kappaB transcription factor recruitment to proinflammatory gene promoters in murine intestinal epithelial cells. J Nutr. 2007; 137: 1208-15.

[76] Ramiro-Puig E, Pérez-Cano FJ, Ramos-Romero S, Pérez-Berezo T, Castellote C, Permanyer J, Franch A, Izquierdo-Pulido M, Castell M. Intestinal immune system of young rats influenced by cocoa-enriched diet. J Nutr Biochem 2008; 19: 55565.

[77] Zunino SJ, Storms DH. Resveratrol alters proliferative responses and apoptosis in human activated B lymphocytes in Vitro. J Nutr. 2009; 139: 1603-08.

20 [78] Ganry O. Phytoestrogen and breast cancer prevention. Eur J Cancer Prev. 2002;11: 519-22.

[79] Gee JM, Johnson IT. Polyphenolic compounds: interactions with the gut and implications for human health. Current Med Chem 2001; 8: 1245-55. 
[80] Scalbert A, Morand C Manach C, Remesy C. Absorption and metabolism of polyphenols in the gut and impact on health. Biomed Pharmacotherapy 2002; 56: 276-82.

[81] Bowey E, Adlercreutz H, Rowland I. Metabolism of isoflavones and lignans by the gut microflora: a study in germ-free and human associated rats. Food Chem Toxicol. 2003; 41: 631-36.

[82] Larrosa M, Luceri C, Vivoli E, Pagliuca C, Lodovici M, Moneti G, Dolara P. Polyphenol metabolites from colonic microbiota exert anti-inflammatory activity on different inflammation models. Mol Nutr Food Res. 2009; 53: 1044-54.

10 [83] Comalada M, Camuesco D, Sierra S, Ballester I, Xaus J, Gálvez J, Zarzuelo A. In vivo quercitrin anti-inflammatory effect involves release of quercetin, which inhibits inflammation through down-regulation of the NF-kappaB pathway. Eur J Immunol. 2005; 35: 584-92.

[84] Cerda B, Espín JC, Parra S, Martínez P, Tomás-Barberán FA. The potente in Vitro antioxidante ellagitannins from pomegranate juice are metabolised into bioavailable but poor antioxidant hydroxy-6H-dibenzopyran-6-one derivatives by the colonic microflora of healthy humans. Eur J Nutr. 2004; 43: 205-220.

[85] Bazzocco S, Mattila I, Guyot S, Renard CM, Aura AM. Factors affecting the conversion of apple polyphenols to phenolic acids and fruit matrix to short-chain fatty acids by human faecal microbiota in vitro. Eur J Nutr 2008; 47: 442-52.

[86] Tzonuis X, Vulevic J, Kuhnle GG, George T, Leonczak J, Gibson GR, Kwik-Uribe C, Spencer JP. Flavanol monomer-induced changes to the human faecal microflora. Br J Nutr. 2008; 99: 782-92. 
[87] Lee HC, Jenner AM, Low CS, Lee YK. Effect of tea phenolics and their aromatic fecal bacterial metabolites on intestinal microbiota. Res Microbiol 2006; 157: 876-84.

[88] Larrosa M, Yañéz-Gascón MJ, Selma MV, González-Sarrías A, Toti S, Cerón JJ, Tomás-Barberán FA, Dolara P, Espín JC. Effect of a low dose of dietary resveratrol on colon microbiota, inflammation and tissue damage in a DSSinduced colitis rat model. J. Agric. Food Chem. 2009; 57: 2211-20.

[89] Medina, E, Garcia, A, Romero, C, de Castro, A, Brenes, M. Study of the anti-lactic acid bacteria compounds in table olives Int J Food Sci Technol 2009; 7: 1286-91.

10 [90] Puupponen-Pimia R, Nohynek L, Hartmann-Schmidlin S, Kähkönen M, Heinonen M, Määttä-Riihinen K, Oksman-Caldentey KM. Berry phenolics selectively inhibit the growth of intestinal pathogens. J. Appl. Microbiol. 2005; 98: 9911000.

[91] Nohynek LJ, Alakomi HL, Kahkonen MP, Heinonen M, Helander IM, OksmanCaldentey KM, Puupponen-Pimiä RH. Berry phenolics: antimicrobial properties and mechanisms of action against severe human pathogens. Nutr. Cancer 2006; 54: 18-32.

[92] Wang WB, Lai HC, Hsueh PR, Chiou RYY, Lin SB, Liaw SJ. Inhibition of swarming and virulence factor expression in Proteus mirabilis by resveratrol. J. Med. Microbiol. 2006; 55: 1313-21.

[93] Parkar SG, Stevenson DE, Skinner MA. The potential influence of fruit polyphenols on colonic microflora and human gut health. Int J Food Microbiol 2008; 124: 295-298. 
[94] Ito Y, Ichikawa T, Iwai T, Saegusa Y, Ikezawa T, Goso Y, Ishihara K. Effects of Tea Catechins on the Gastrointestinal Mucosa in Rats. J Agric Food Chem 2008; 56: $12122-6$. 
Table 1. Phytochemicals and physiological function

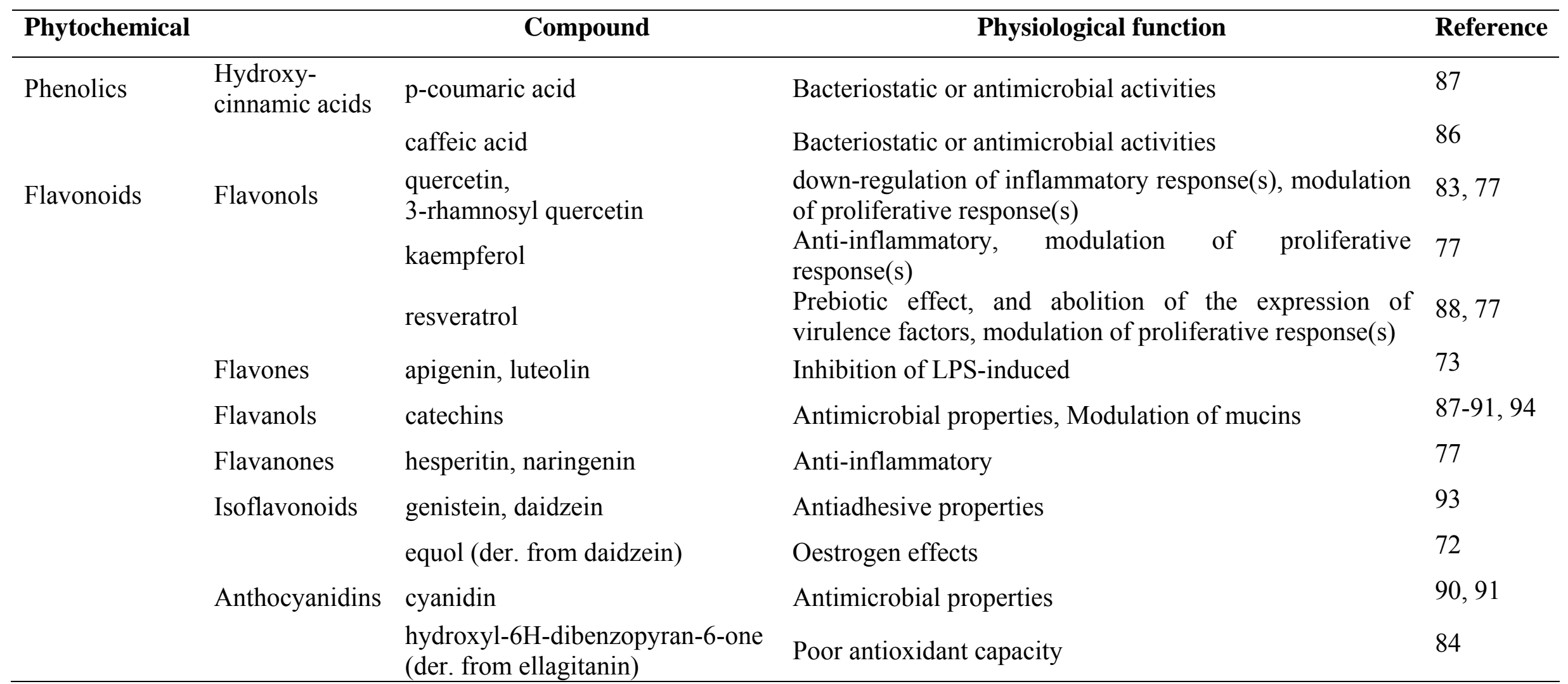


Figure legends

Figure 1. Interactions between functional food components and the gut microbiota.

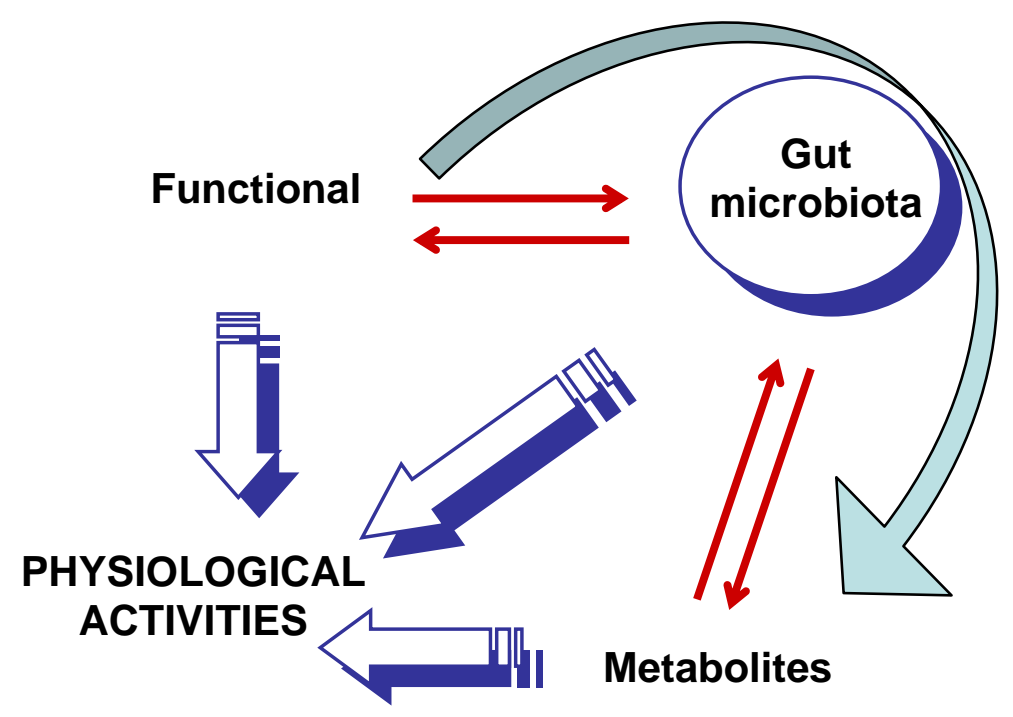

